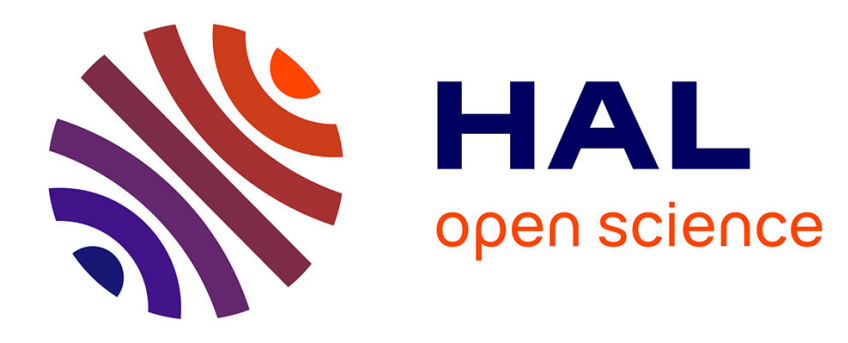

\title{
Identification of an Age Maturity in Time Discrimination Abilities
}

Quentin Hallez, Sylvie Droit-Volet

\section{To cite this version:}

Quentin Hallez, Sylvie Droit-Volet. Identification of an Age Maturity in Time Discrimination Abilities. Timing \& Time Perception Reviews, 2020, pp.1-21. 10.1163/22134468-bja10017 . hal-02978399

\section{HAL Id: hal-02978399 \\ https://hal.science/hal-02978399}

Submitted on 9 Nov 2020

HAL is a multi-disciplinary open access archive for the deposit and dissemination of scientific research documents, whether they are published or not. The documents may come from teaching and research institutions in France or abroad, or from public or private research centers.
L'archive ouverte pluridisciplinaire HAL, est destinée au dépôt et à la diffusion de documents scientifiques de niveau recherche, publiés ou non, émanant des établissements d'enseignement et de recherche français ou étrangers, des laboratoires publics ou privés. 
THE AGE OF MATURITY IN TIME DISCRIMINATION ABILITIES

\title{
Identification of an age maturity in time discrimination abilities
}

\author{
Quentin Hallez ${ }^{1}$ and Sylvie Droit-Volet ${ }^{1}$
}

${ }^{1}$ University Clermont Auvergne, CNRS, UMR 6024, Clermont-Ferrand, France

Timing \& Time Perception (2020). https://doi.org/10.1163/22134468-bja10017

To whom correspondence should be addressed:

E-mail: sylvie.droit-volet@uca.fr, quentin.hallez@gmail.com 


\title{
THE AGE OF MATURITY IN TIME DISCRIMINATION ABILITIES
}

\begin{abstract}
The aim of this study was to identify the age at which parameters of timing performance in a temporal bisection task converge on an adult-like stable level. Participants in the three- to 20year-old range were tested using a temporal bisection task with sub-second and supra-second durations. The data were divided into two samples. In the first sample, all participants were integrated into the analysis regardless of their success. In the second sample, only performers were inserted. The point of subjective equality (PSE) and the Weber Ratio (WR) were analyzed for each participant in each sample. By fitting a mathematical model to these parameters as a function of age, we showed that the PSE did not reach stability for the long durations due to a great inter-individual difference in the bisection point (BP) at these temporal values, while it reached a stable level for short durations in both samples. Yet, the stability points associated with the short duration BPs were reached in both samples. Interestingly, the stabilization points on WR converge earlier for the sample associated with the performers compared to the sample with no preselection. Nonetheless, time sensitivity (WR) shows a similar pattern through the two samples as adult-like performance appeared at an earlier age for short durations. The more gradual change in temporal performance for the long durations was explained by the processing of these durations, that requires attention and working memory capacities, which increase with age.
\end{abstract}

Keywords: Timing, time perception, development, bisection task 


\section{THE AGE OF MATURITY IN TIME DISCRIMINATION ABILITIES}

\section{Introduction}

The last few decades have shown a growing body of studies aimed at describing the development of timing abilities in children. These developmental studies have usually compared children's temporal performance in two or three different age groups (e.g. five, eight and 10 years), where age had been partly chosen arbitrary. However, they did not offer the means to identify the age at which timing performance really converged on an adult-like stable level. The aim of our study was to fill this gap by modelling the development curve of the temporal performances of a large sample, ranging from children of three years old to young adults of 20 years old.

It is important to identify a key age from which there is no further change in the development of temporal capacities. From a clinical perspective in particular, an increasing number of studies has highlighted the critical role of temporal abilities in cognitive disorders such as dyslexia or schizophrenia (Casini et al., 2018; Giersch et al., 2016; Giersch \& Mishara, 2017; Roy et al., 2012). Several studies have indeed shown the close relationship between temporal sensitivity and individual cognitive capacities (for a review see Droit-Volet, 2013, 2016). By assessing children's cognitive abilities with different neuropsychological tests, they have shown that the children who were most variable in temporal estimates were also thos who had fewer resources for attention and memory (e.g., Droit-Volet \& Coull, (2016; Droit-Volet \& Zélanti, 2013a,b; Zélanti \& Droit-Volet, 2011). Similarly, the greatest distortions in time estimates are observed in children with lower attention and working memory capacities (DroitVolet \& Zélanti, 2013a; Droit-Volet et al., 2015; Hallez \& Droit-Volet, 2017, 2019; Zélanti \& Droit-Volet, 2011, 2012). The detection of delay in the development of temporal discrimination capacities compared to a reference age (development norm), with a temporal discrimination task that is easy to use with young children, should therefore allow early diagnosis of children with temporal processing difficulties. This early identification of temporal developmental delays would allow temporal rehabilitation that reduces the consequences of time deficits on cognitive development and learning.

In order to model the developmental trajectory of time abilities, we tested a large population of participants aged between three and 20 years. The timing performance curve as a function of age obviously changes according to the task used. In the present study we decided to ecamine children's performance in the temporal bisection task (Allan \& Gibbon, 1991; Wearden, 1991). Droit-Volet et al. (2015) showed that this task initially used in animals (Church \& Deluty, 1977), is the least cognitively demanding of the temporal tasks used in verbal children (i.e, temporal generalization, temporal reproduction). In this task, participants are trained to discriminate a short (S) from a long (L) standard duration. Then they are presented with probe durations (D) which are equal to $\mathrm{S}$ or $\mathrm{L}$ or of intermediate values, and their task is simply to judge whether $\mathrm{D}$ is more similar to $\mathrm{S}$ or $L$ by responding short or long.

The temporal bisection task was firstly used by McCormack et al. (1999) in children aged five, eight, and 10 years with one short duration range $(200 / 800 \mathrm{~ms})$, and then by DroitVolet and Wearden (2001) in children aged three, five and eight years with two longer duration ranges (1/4-s and 2/8-s). The results of these two studies indicated that the major developmental difference in temporal bisection lies in time sensitivity, which significantly improves with age, being lower in the five-year-olds than in the eight-year-olds. The results have been replicated in a long series of at least 25 studies performed in typically developed children (e.g., DroitVolet, 2017; Droit-Volet \& Izaute, 2009; Droit-Volet \& Rattat, 2007; Droit-Volet \& Wearden, 2002; Droit-Volet \& Zélanti, 2013a, b; Droit-Volet et al., 2004, 2008; Rattat \& Droit-Volet, 


\section{THE AGE OF MATURITY IN TIME DISCRIMINATION ABILITIES}

2005; Zélanti \& Droit-Volet, 2011, 2012). However, we do not know much about the progression in temporal performance between 8eight years and adulthood, most studies having simply compared a group of 8eight-year-olds with a group of adults. In addition, some studies found a difference in time sensitivity between these two age groups, while others did not. The description of the developmental curve in the temporal bisection task is thus still incomplete.

The timing performance curve as a function of age is also supposed to change according to stimulus durations to be processed. Zélanti and Droit-Volet (2011) found earlier temporal discrimination abilities for the short than for the long stimulus durations in the temporal bisection task (with the same 1:2 S/L ratio). By assessing individual cognitive capacities with a series of neuropsychological tests, they demonstrated that the processing of long durations requires more working memory and attention capacities than that of short durations. Indeed, the brain imaging studies suggested that different cerebral structures are involved in the processing of short and long durations (Coull \& Droit-Volet, 2018; Lewis \& Miall, 2009; Merchant et al., 2013). For example, the anterior prefrontal cortex is particularly involved in the judgment of long durations and this brain area is known to play an important role in attention control (Dempster \& Brainerd, 1995; Mundy, 2018). Furthermore, the prefrontal cortex progressively develops throughout childhood, reaching a critical period at about seven to eight years (Casey et al., 2005; Sowell et al., 1999; Tsujimoto, 2008). In sum, the timing performance curve should stabilize faster fort short durations than for long ones.

The studies that have addressed the development of abilities to discriminate durations have tested only two or three groups of participants of different ages. The main cause is the methodological difficulty of testing a large number of children ranging from three years through to adulthood. Another cause lies in the challenge of finding new mathematical ways that go beyond a simple regression to successfully identify a threshold above which temporal performance is stabilized, i.e., as of which no further age-related changes occur. This is the purpose of this study in which a large sample of participants aged from three to 19 years was tested on two bisection tasks, one with a short- duration range $(0.5 / 1 \mathrm{~s})$ and the other with a longer one $(5 / 10 \mathrm{~s})$.

\section{Participants}

\section{Method}

The sample consisted of 119 participants aged from three to 20 years ( 66 girls and 53 boys): 8 three-year-olds, 15 four-year-olds, 17 five-year-olds, 9 six-year-olds, 5 seven-yearolds, 10 eight-year-olds, 10 nine-year-olds, 10 10/11-year-olds, 7 12/13-year-olds, 6 15/16year-olds, 12 17/18-year-olds and 10 19/20-year-olds. The participants were recruited in the Région Auvergne in France from the social environments of researchers (including $\mathrm{PhD}$ students) at the University Clermont-Auvergne. All the participants were volunteers and signed written informed consent (parents signed on behalf of their children). This study was carried out according to the principles of the Helsinki Declaration.

\section{Material and Procedure}

The participants were seated in a quiet room in front of a computer with a 15 " square screen. E-prime 2.0 software (Schneider et al., 2002) generated the experiment and recorded the responses. The stimulus to be timed was a blue circle ( $4.5 \mathrm{~cm}$ diameter), presented in the center of the computer screen. Responses were made on the " $d$ " and " $k$ " keys of the computer keyboard on which stickers depicting a small or a larger circle indicated "short" or "long".

All the participants completed two bisection tasks, one for the short durations $(0.5 / 1-\mathrm{s})$ and the other for the long durations $(5 / 10-\mathrm{s})$. The task order was counterbalanced across subjects, with a 15-minutes break between each task. For the short durations, the short anchor duration (S) was $0.5 \mathrm{~s}$ and the long anchor duration (L) $1.0 \mathrm{~s}$. The probe durations were 0.5 , 


\section{THE AGE OF MATURITY IN TIME DISCRIMINATION ABILITIES}

$0.58,0.67,0.75,0.83,0.92$, and $1.0 \mathrm{~s}$. For the long durations, $\mathrm{S}$ and $\mathrm{L}$ were 5.0 and $10 \mathrm{~s}$, respectively, and the probe durations: 5.0, 5.83, 6.67, 7.5, 8.33, 9.17 and $10 \mathrm{~s}$.

In each bisection task, the participants were given a 10-trial training phase and a 70-trial testing phase. In the training phase, they were trained to respond "short" or "long" after S and L, by pressing the corresponding key. This number of training trials has been shown to be sufficient for discrimination between S and L, even in younger children (Droit-Volet \& Rattat, 2007; Droit-Volet \& Wearden 2001). Key-press assignments were counterbalanced across subjects. In the testing phase, the task was similar, i.e. responding "short" or "long" when the participants judged that the probe duration was more similar to S or L, respectively. In the testing phase, the participants performed 10 blocks of seven randomly presented trials, one trial for each probe duration. A trial was initiated by the word "prêt/ready" presented on the computer's screen and spoken by the experimenter. When the participant was genuinely ready, the experimenter pressed the spacebar and the visual stimulus was displayed after $600 \mathrm{~ms}$. The experimenter also told the participants not to count because counting time can bias the data (Rattat \& Droit-Volet, 2012).

\section{Data analysis}

Statistical analyses were performed on two indices of bisection performance: The bisection point (BP) and the Weber Ratio (WR). The BP is the "psychological mid-point" of the duration range between $\mathrm{S}$ and $\mathrm{L}$ (Wearden, 2016, p. 72). It is the stimulus duration giving rise to $50 \%$ of "short" responses and $50 \%$ of "long" responses. The WR is an index of time sensitivity. This index was obtained by subtracting the stimulus duration given rise to a $\mathrm{p}$ (long) of 0.25 from the stimulus given rise to a $p$ (long) of 0.75 , dividing this difference by 2 , and then dividing that quotient by the BP. A high WR indicates a low time sensitivity and a low WR a higher time sensitivity. These two indexes were derived from the fit of the Pseudo-Logistic Model (PLM) with the individual psychophysical functions (Killeen, et al., 1997) as it usually provides an excellent account of bisection data in a large population of subjects (Allan \& Gerhardt, 2001; Brown et al., 2011). In addition, Wearden and Ferrara (1995) demonstrated that the results were quite similar whatever the method used. We have drawn a development trajectory for each of these two indices. This development trajectory was obtained with the simplex algorithm method, also known as the Nelder-Mead method (Nelder \& Mead, 1965). This method allows us to optimize the fit of a function by finding the curve that best fits the data, that is, the function with the smallest squared error between the curve and the data.

For each index of temporal performance, we initially examined the significant of the relationship between age (in months) and performance using a simple linear regression for BP and WR. This analysis makes it possible to assess the significance of the evolution of performance with increasing age in the range from three to 20 years. However, it does not allow us to identify the age at which performance stabilizes, forming a plateau, which could be an indicator of the attainment of maturity. In order to find the aspect of the curves to fit both WR and BP data, we used the Matlab curve-fitting toolbox (Qiang \& Zhang, 2015). The program revealed that the evolution of the performance curve as a function of participants' age followed either an increasing (BP) or decreasing (WR) exponential law (e.g., exponential decay function) in accordance with the functions $\left\{\mathrm{a}^{*} \exp [-(x-b) / \tau)+c\right\}$ and $\mathrm{a}\{(1-\exp [-(x-b) / c]\} *\{\exp [-(x-$ $d) / \tau]+e\}$, respectively. We found similar functions when using other methods (e.g., the Python SciPy toolbox). We then used the Nelder-Mead simplex algorithm (downhill simplex algorithm) in the scipy.optimize.fmin package of Python. The Nelder-Mead method is an 


\section{THE AGE OF MATURITY IN TIME DISCRIMINATION ABILITIES}

algorithm that optimizes the fit of a function (Lagarias, Reeds, Wright et al., 1998; Nelder \& Mead, 1965; Olsson \& Nelson, 1975). It automatically converges towards the best parameter values by minimizing the sum of the squares of the differences between the data and the model. Calculated functions (continuous lines) fitted to the data (dotted lines) are available in Figure 2 and Figure 4. The interest of the exponential shape functions lies in the fact that there is a constant time $(\tau)$, where $\tau$ is the $\mathrm{x}$ value of the origin of the tangent (Berg \& Ditlevsen, 2013; Kasprowicz et al., 2012; Rall, 1960; Tiganj, Hasselmo, \& Howard et al., 2015). After a period of one constant time $(1 \tau)$, the function reaches approximately $37 \%$ of its final value. After a period of five constant times $(5 \tau)$, the function reaches a value less than $1 \%$ from its asymptote. Consequently, $5 \tau$ is considered to represent a threshold beyond which differences are no longer significant (Lipták, 2003). This function has been used extensively in recent years to model mnemic phenomena since, from a certain duration, there is no longer any forgotten memory (Kahana \& Adler, 2017; Zylberberg, Dehaene, Mindlin \& Sigman et al., 2009). This is the same technique that we have used in our study in order to estimate the age from which a stabilization of performance is observed, i.e., the age at which some parameters of judgment in temporal bisection cease to change. Given that there are 324 months from 3three to 19 years old and that our sample was made of 119 participants, we averaged performance by age in months when there was more than one representative. It is nonetheless important to highlight that not having a representative for each age group in months (at 14 years for example) is not problematic, because the strength of curve-fitting is precisely to be able to generalize on the basis of the available data (Cheyne \& Worrall, 2006; Forster \& Sober, 1994).

We decided to find the fitting function for two samples of our participants (Table 1). For the first sample, $9 \%$ in the short- duration condition (i.e., 5 participants aged three years, 3 aged four years, 2 aged five years and 1 aged seven years) and $18 \%$ in the long- duration condition (i.e., 5 participants aged three years, 1 aged four years, 6 aged five years, 3 aged six years, 1 aged seven years, 1 aged nice years and one aged 19 years) were excluded from the statistical analyses (from the 119 participants) because they always responded short or long, giving a totally flat bisection function (i.e., $\mathrm{R}^{2}$ non-significant). This resulted in a final sample of 108 and 91 participants in the short and the long- duration condition, respectively (mean $\mathrm{R}^{2}$ $=0.80$ ). However, in this sample, we may also include children who did not produce a flat bisection function, but whose performance remains poor probably because they have sometimes answered randomly short and long. Although the proportion of random responses is higher in children than in adults (Droit-Volet \& Wearden, 2001), we decided to also examine a second sample without these children. In order to found find out the children who certainly did not respond randomly we excluded participants showing a BP higher or lower than the anchor durations ( $\mathrm{S}$ and $\mathrm{L}$ ). This second sample consisted of an additional exclusion from the first sample of 8 subjects in the short-duration condition (i.e., 2 participants aged three years; 4 aged four years, one aged five years and 1 aged 6six years) and 4 subjects in the long-duration condition (i.e., 1 participant aged three years, 3 aged five years). This thus represented a total exclusion of $27 \%$ of the initial participant sample (mean $\mathrm{R}^{2}=0.82$ ). 


\section{THE AGE OF MATURITY IN TIME DISCRIMINATION ABILITIES}

\section{Table 1}

Mean (M) and Standard Deviation (SD) for bisection point (BP) in ms and Weber Ratio (WR) for each age range of the sample 1 with all the participants (excluded those who responded always short or long for the different stimulus durations) and the sample 2 (sample 1 minus "bad performers").

\begin{tabular}{|c|c|c|c|c|c|c|c|c|}
\hline & \multicolumn{4}{|c|}{ Short Durations } & \multicolumn{4}{|c|}{ Long Durations } \\
\hline & \multicolumn{2}{|c|}{$\mathrm{BP}$} & \multicolumn{2}{|c|}{ WR } & \multicolumn{2}{|c|}{ BP } & \multicolumn{2}{|c|}{ WR } \\
\hline & $M$ & $S D$ & $M$ & $S D$ & $M$ & $S D$ & $M$ & $S D$ \\
\hline \multicolumn{9}{|l|}{ Sample 1} \\
\hline $3-4$ years & 615 & 291 & 1.08 & 0.89 & 6087 & 2192 & 0.97 & 1.09 \\
\hline $5-6$ years & 700 & 152 & 0.23 & 0.17 & 6603 & 1946 & 0.41 & 0.38 \\
\hline $7-8$ years & 705 & 65 & 0.16 & 0.06 & 6277 & 949 & 0.22 & 0.10 \\
\hline $9-10$ years & 743 & 82 & 0.15 & 0.06 & 6796 & 993 & 0.21 & 0.11 \\
\hline $11-12$ years & 754 & 65 & 0.14 & 0.03 & 6938 & 437 & 0.28 & 0.21 \\
\hline $13-15$ years & 757 & 34 & 0.15 & 0.09 & 7173 & 430 & 0.23 & 0.04 \\
\hline $16-17$ years & 736 & 29 & 0.12 & 0.05 & 6766 & 450 & 0.19 & 0.14 \\
\hline $18-20$ years & 729 & 49 & 0.10 & 0.03 & 7044 & 364 & 0.18 & 0.13 \\
\hline \multicolumn{9}{|l|}{ Sample 2} \\
\hline $3-4$ years & 665 & 150 & 0.60 & 0.87 & 6422 & 2197 & 1.0 & 0.81 \\
\hline $5-6$ years & 695 & 119 & 0.24 & 0.17 & 6762 & 1157 & 0.30 & 0.12 \\
\hline $7-8$ years & 705 & 65 & 0.16 & 0.06 & 6277 & 949 & 0.22 & 0.11 \\
\hline $9-10$ years & 743 & 82 & 0.15 & 0.06 & 6796 & 993 & 0.21 & 0.11 \\
\hline $11-12$ years & 754 & 65 & 0.14 & 0.03 & 6938 & 437 & 0.28 & 0.21 \\
\hline $13-15$ years & 757 & 35 & 0.16 & 0.09 & 7173 & 431 & 0.23 & 0.04 \\
\hline $16-17$ years & 736 & 29 & 0.12 & 0.05 & 6766 & 450 & 0.19 & 0.14 \\
\hline $18-20$ years & 729 & 48 & 0.10 & 0.03 & 7044 & 364 & 0.18 & 0.13 \\
\hline
\end{tabular}

\section{Bisection Point}

\section{Results}

Figure 1 shows the mean and the standard deviation of the BP for each age year in the range from three to 20 years for the short and the long duration condition for all participants (first sample). There was significant regression between the age and the BP for both the short, $\mathrm{F}(1,107)=5.37, \mathrm{p}=0.02, \eta^{2}=0.05$, and the long durations, $\mathrm{F}(1,90)=21.23, \mathrm{p}<0.001, \eta^{2}=$ $0.17(B=0.0005, \mathrm{SE}=0.0002, \beta=0.22, t=2.32, p=0.02 ; B=0.004, \mathrm{SE}=0.002, \beta=0.22, t$ $=2.14, p=0.03$, respectively). Participants' BP thus increases by 0.0005 and 0.004 for each month of age. This suggests a slightly shift in the BP value to the right during childhood. However, when the regression analyses were carried out on the second sample (selected sample), the regression equations proved a non- significant link between the age and the BP for both the short, $F(1,99)=2.09, p>0.05$, and the long durations, $F(1,86)=3.93, p>0.05$. As discussed later, this suggests that age-related difference in BP bisection was mainly due to a small proportion of young children who were unable to perform the task.

The fit of BP data (sample 1) with the results of our function $\left\{a^{*} \exp [-(x-b) / \tau]+c\right\}$ allows us to identify the age at which the BP value ceases to change. For the short durations, 


\section{THE AGE OF MATURITY IN TIME DISCRIMINATION ABILITIES}

the best predictor parameters were $a=0.72, b=48.25, \tau=0.71, c=0.0004$, Sum $_{\text {squares }}=1.16$, $\mathrm{LSD}=0.01$, and for the long duration $a=6.89, b=142.30, \tau=34.72, c=0.10$, Sum $=59.09$, $\mathrm{LSD}=0.83$. The values of the least least-squares indices ( Sum $_{\text {squares }}$ and LSD) accounting for the differences between the empirical data and the adjusted model indicated a good fit for the function with the data for the short durations. Although there is no law or mathematical process allowing us to decide from when on the model is significantly different from the empirical data, it appears that the least-squares indices are higher for the long durations. This indicates important inter-individual differences in the BP values for the long durations. In our function, $5 \tau$ is equal to $5^{*}(\tau+b)$. Therefore, for the short duration, $5 \tau=51.8\left(5^{*} 0.71+48.25=51.8\right)$. In other words, the BP value no longer varied from the age of 52 months (4.3 years), and systematically converged toward a $\mathrm{BP}$ value of $0.716 \mathrm{~s}$, which is close to the geometric $\operatorname{mean}(\sqrt{0.5} \times 1=0.707$ (Figure 2$)$. 

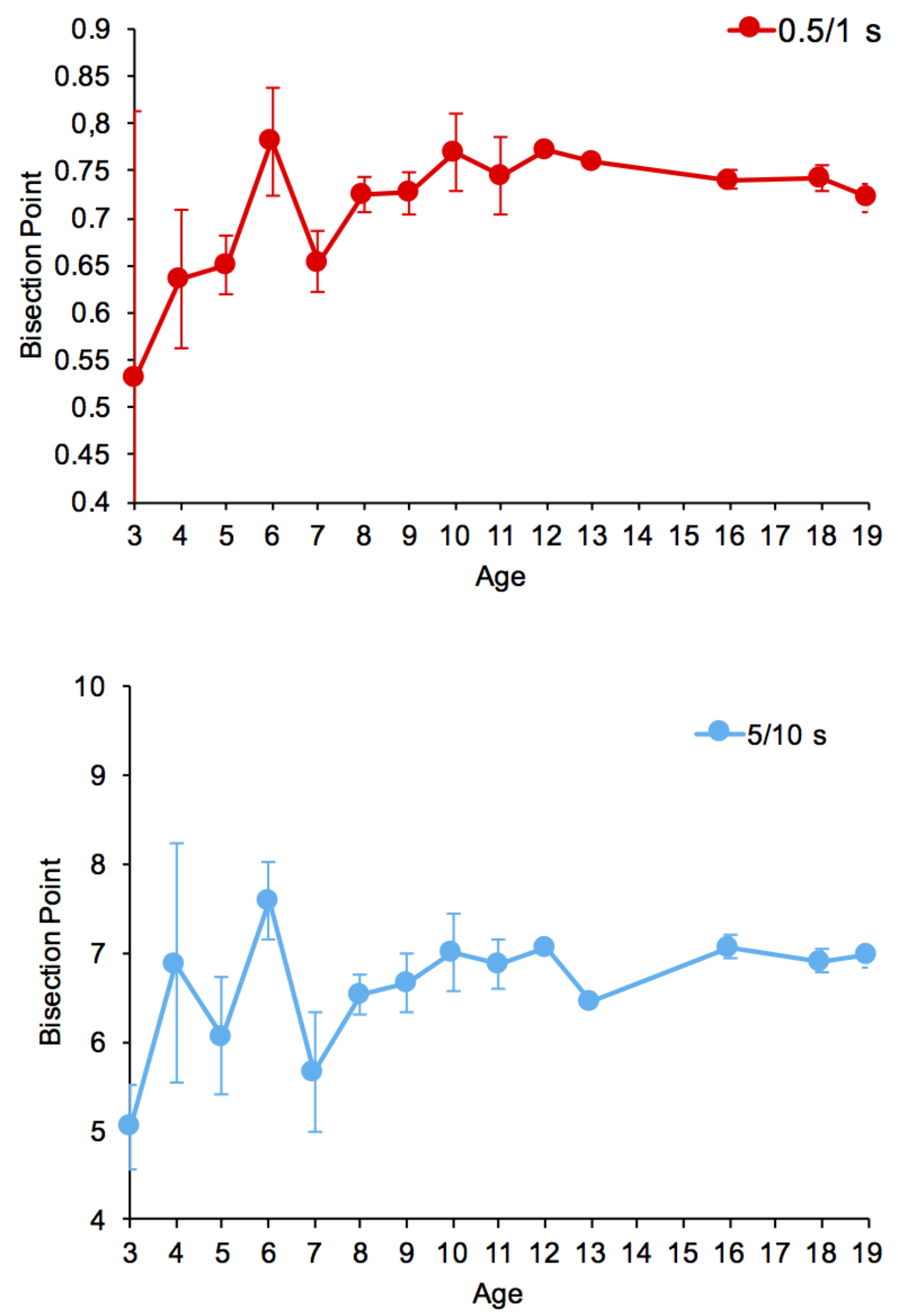

Figure 1. Mean bisection points with standard deviation materialized by the error bars for 
THE AGE OF MATURITY IN TIME DISCRIMINATION ABILITIES

each age year going from 3 to 19 years, for the short (0.5/1.0- s) and the long (5/10- s) duration condition.
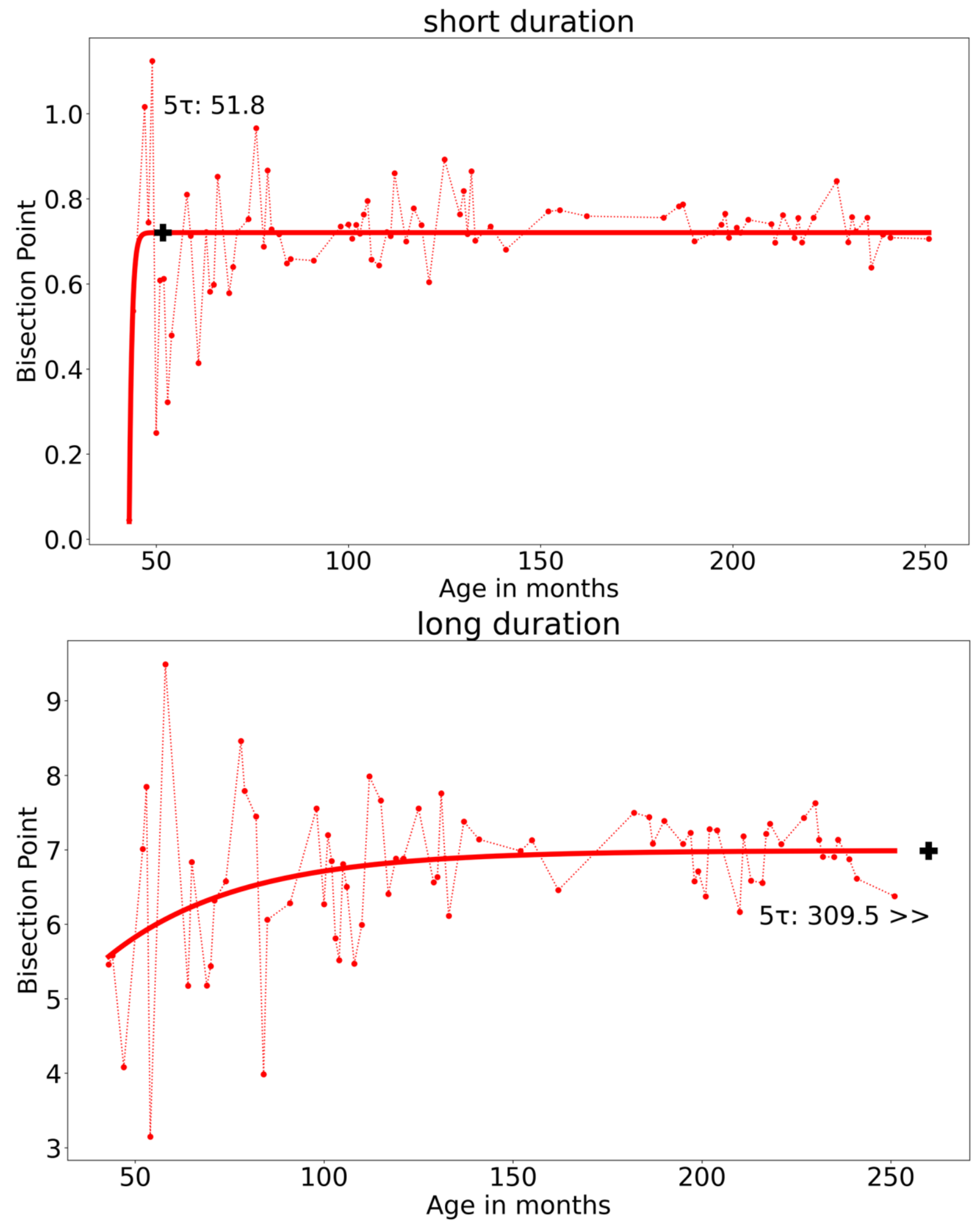

Figure 2. Empirical data (dotted lines) and fitted functions (continuous lines) of the bisection points plotted against the participants' age in months for the short $(0.5 / 1.0-\mathrm{s})$ and the long 


\section{THE AGE OF MATURITY IN TIME DISCRIMINATION ABILITIES}

(5/10- s) duration condition associated with the first sample. The black cross indicates the $5 \tau$ value.

For the long duration, the BP would reach its final value $(y=69.76)$ at the age of 316 months $(5 * 34.72+142.30=315.9)$, suggesting great inter-individual differences in BP values across all ages (Figure 2). The inter-individual variability in the BP value was therefore lower for the short than for the long durations. The point of subjective equality (PSE) in temporal bisection thus reached a value characteristic of that of adults at the early age of four years for the short duration and never reached a stabilization point for the long duration. Both of these findings are consistent with the results of studies showing the absence of a significant agerelated differences in the BP.

As show in Figure 3, the model based on our second sample showed a later convergence for short durations, with $5 \tau=194.0(16.17$ years $)\left(5^{*} 21.51+86.43=194.0\right.$, with the parameters $\left.a=0.03, b=86.43, \tau=21.51, c=0.71 \mathrm{Sum}_{\text {squares }}=0.51, \mathrm{LSD}=0.005\right)$, while the program similarly fails to reach convergence for long durations with roughly $5 \tau=1, .1903656056979$ ${ }^{\mathrm{e}+11}\left(5^{*} 1.73981761^{\mathrm{e}+10}+3.20456803^{\mathrm{e}+10}=1.1903656056979^{\mathrm{e}+11}\right.$, with the parameters $a=$ $2.91542124^{\mathrm{e}+06}, \mathrm{~b}=3.20456803^{\mathrm{e}+10}, \tau=1.73981761^{\mathrm{e}+10}, c=1.54765371^{\mathrm{e}+07}$. As discussed later, these results suggest a large inter-individual variability in the PSE in the temporal bisection task, such that it does not stabilize with increasing age, i.e., during the significant period of development.

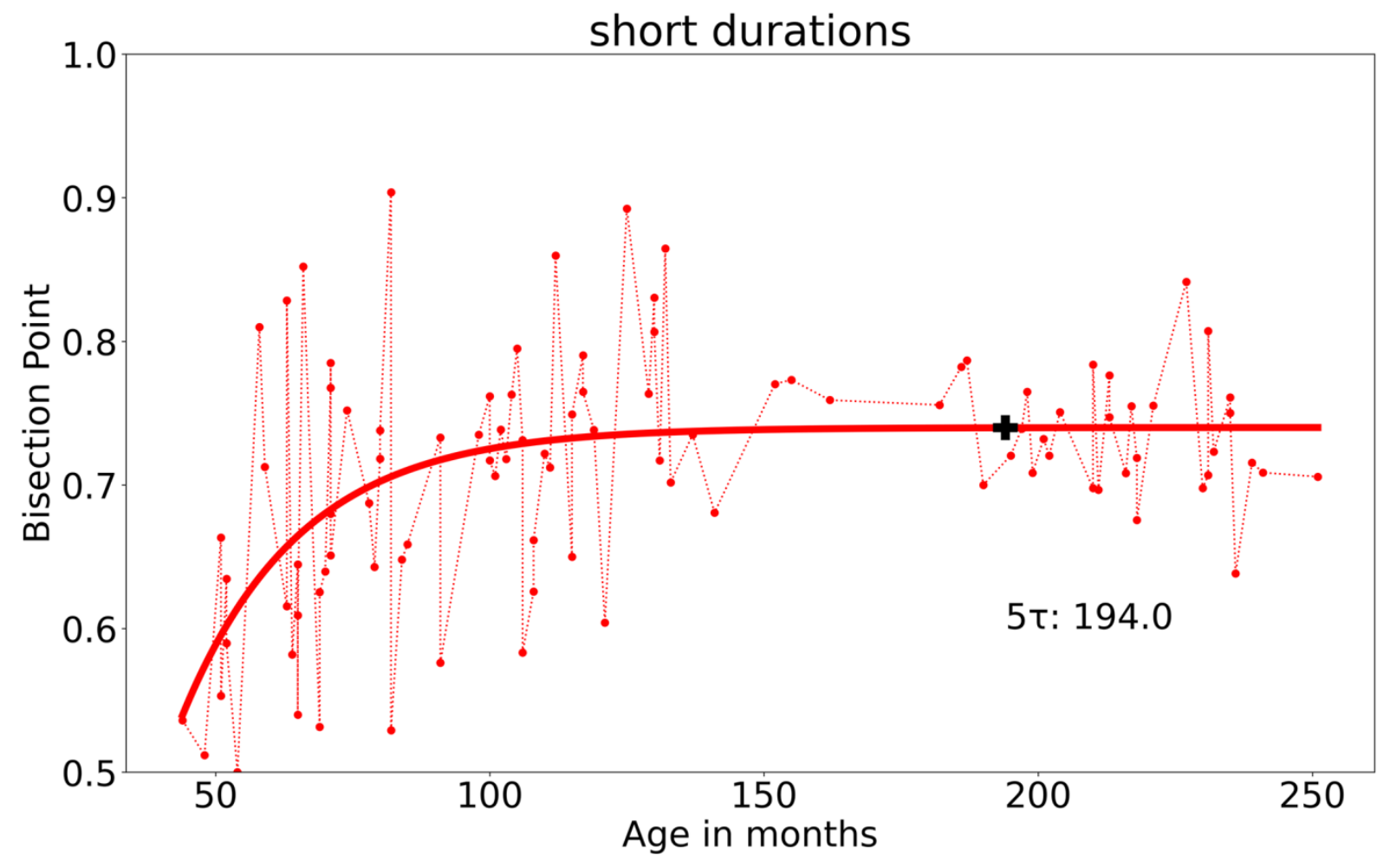

Figure 3. Empirical data (dotted lines) and fitted functions (continuous lines) of the bisection points plotted against the participants' age in months for the short $(0.5 / / 1.0-\mathrm{s})$ and the long $(5 / / 10-s)$ duration condition associated with the selected sample. The black cross indicates the $5 \tau$ value 


\section{THE AGE OF MATURITY IN TIME DISCRIMINATION ABILITIES}

\section{Weber Ratio}

Figure 4 shows the mean and standard deviation of the WR for the different ages in the short and the long duration condition for all participants (sample 1). The regression analyses indicated that the time sensitivity was a function of age for both the short, $F(1,107)=21.23, p$ $<.001, \eta^{2}=0.17$ and the long durations, $\mathrm{F}(1,90)=11.01, p=0.001, \eta^{2}=0.11$. For each month of age, the WR value decreased 0.003 points and 0.002 for each age in month for the short and the long duration, respectively (short duration: $B=-0.003, \mathrm{ES}=0.001, \beta=-0.41, t=-4.61, p$ $<0.001$; long duration: $B=-0.002, E S=0.001, \beta=-0.33, \mathrm{t}=-3.32, \mathrm{p}=0.001)$. Therefore, the WR decreased significantly as children grow older, indicating a progressive improvement of sensitivity to time with increasing age from three to 20 years. Similar results were found for the second sample (selected sample), with a significant regression equation for both the short $F(1$, $99)=17.22, p<0.001, \eta^{2}=0.15$, and the long durations, $F(1,86)=7.31, p=0.008, \eta^{2}=0.08$. $(B=-0.002, \mathrm{ES}=0.001, \beta=-0.39, \mathrm{i}=-4.15, \mathrm{i}<0.001 ; B=-0.002, \mathrm{ES}=0.001, \beta=-0.28, \mathrm{i}=-$ $2.70, p=0.008$, respectively). The increase in time sensitivity with age is thus a robust effect observed in all samples.

The modeling of WR data for the first sample suggests that the children reached an adult-like time sensitivity at the age of six years for the short durations and $81 / 2$ years for the long durations. To establish these ages, we did not use the function described above $\left\{\mathrm{a}^{*} \exp [-\right.$ $(x-b) / \tau]+c\}$ because it did not fit well with our data, due to the great inter-individual variability in the WR values in children younger than five years (60 months). As previously suggested (based on the Matlab curve-fitting toolbox as well as the python SciPy toolbox), a better fit can be obtained by using a reversed exponential function, thus keeping the advantage of a time constant, i.e. $\mathrm{a}\{1-\exp [-(x-\mathrm{b}) / \mathrm{c}]\} *\{\exp [-(x-\mathrm{d}) / \tau]+\mathrm{e}\}$. 
THE AGE OF MATURITY IN TIME DISCRIMINATION ABILITIES

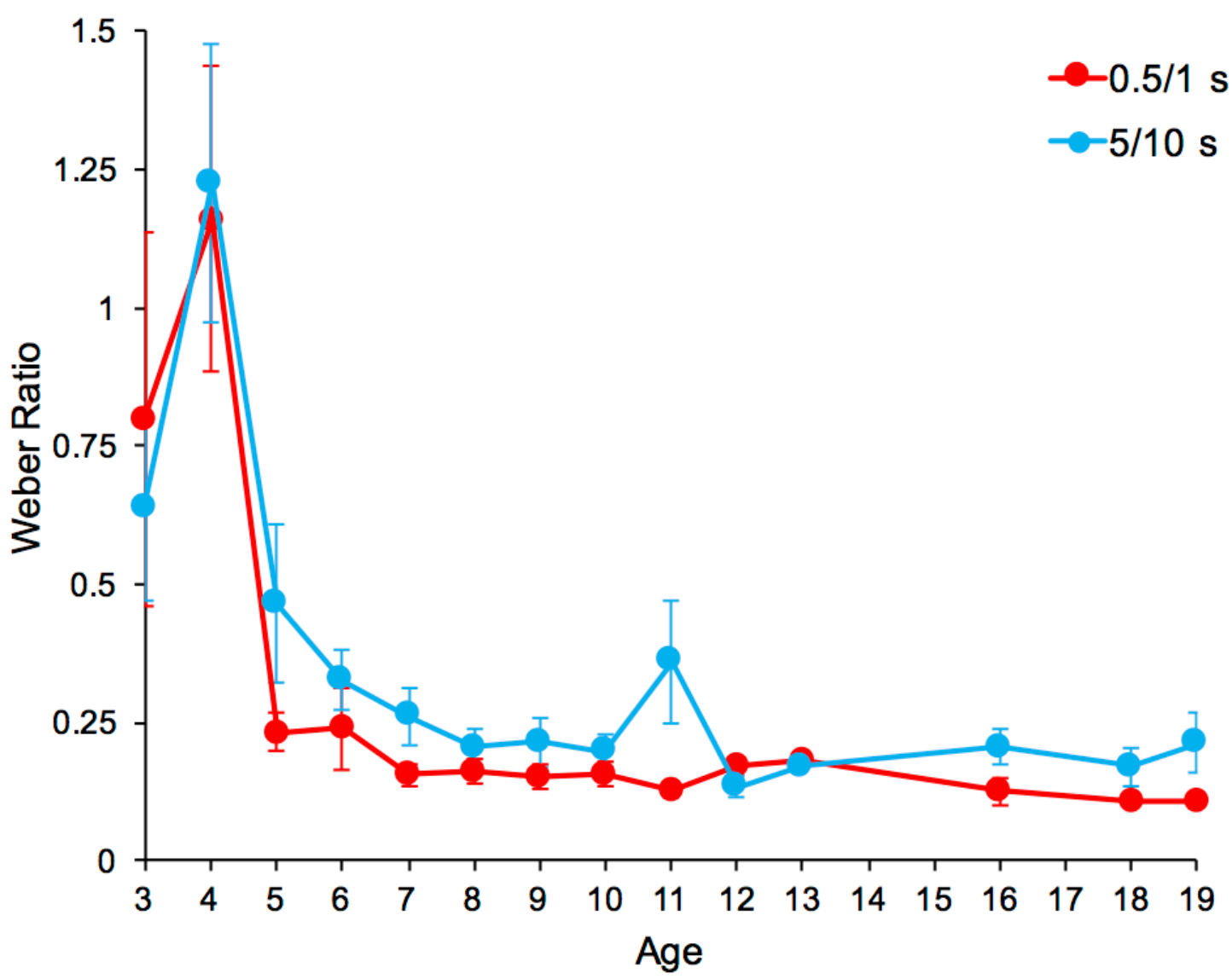

Figure 4. Mean Weber Ratio with standard deviation indicated by the error bars for each age year going from 3 to 19 years, for the short (0.5/1.0 -s) and the long (5/10 -s) duration condition.

The final functions were therefore $48.64 *\{1-\exp [-(x-43.08) / 7025.46]\} *\{\exp [-(\mathrm{x}-$ $60.98) / 3.33]+0.14], \operatorname{Sum}_{\text {squares }}=4.30, \mathrm{LSD}=0.05$, for the short durations, and $113.15^{*}\{1-$ $\exp [-(x-42.58) / 23098.98]\} *\{\exp [-(\mathrm{x}-72.31) / 6.50]+0.21\}, \mathrm{Sum}_{\text {squares }}=7.55, \mathrm{LSD}=0.11$, for the long durations. Thus, for the short durations, $5 \tau$ is equal to $77.7(5 * 3.33+60.98=77.7)$. In sum, at six years (77.7 months) the WR value has reached a value that no longer changes despite the increase in age, with a WR close to 0.21 (Figure 5). For the long duration, the asymptote was similar $(y=0.21)$, but it converged later, at the age of 8.75 years $(105$ months $)(5 * 6.50+$ 72.31). 
THE AGE OF MATURITY IN TIME DISCRIMINATION ABILITIES
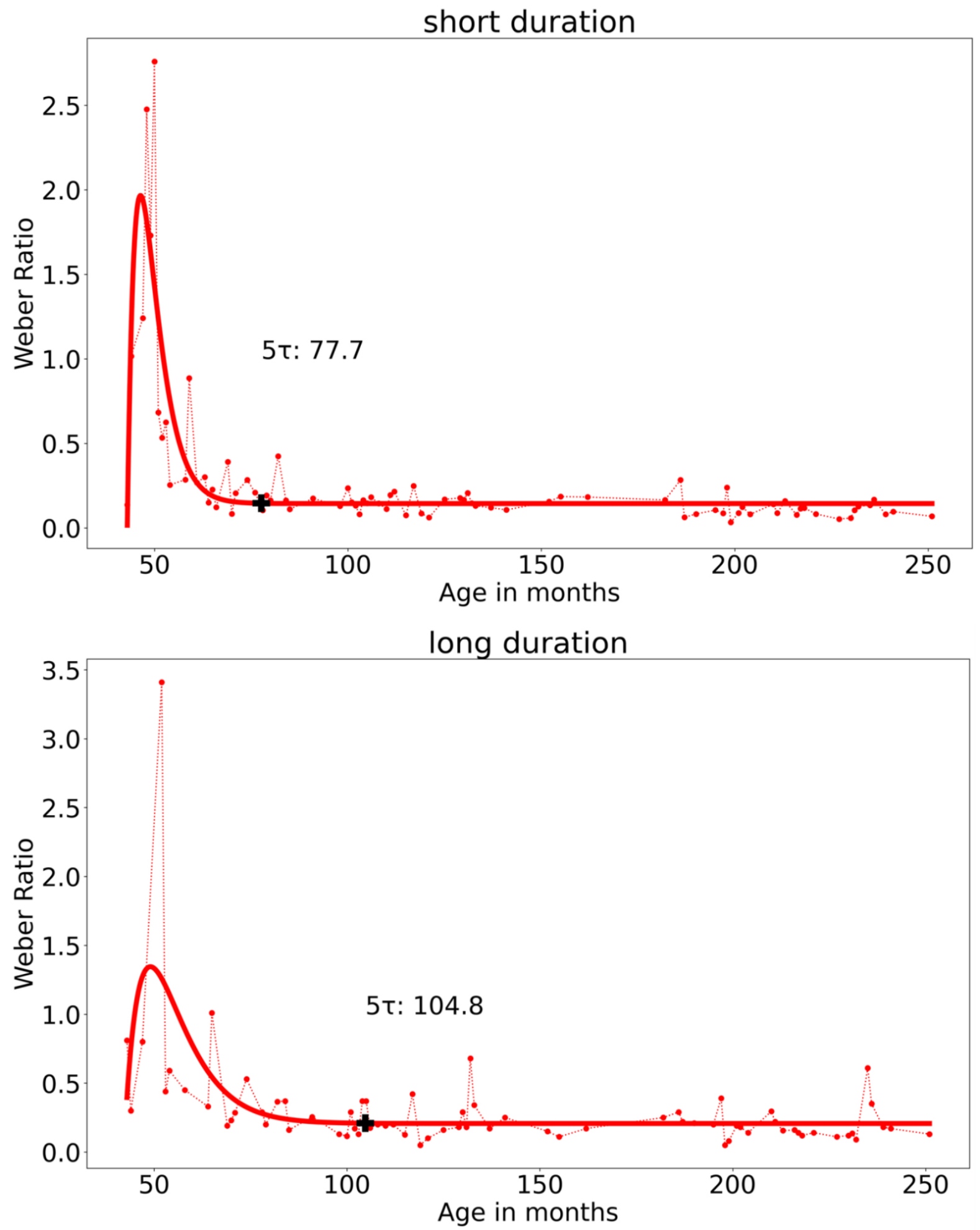

Figure 5. Empirical data (dotted lines) and fitted functions (continuous lines) of the Weber Ratio plotted against the participants' age in months for the short $(0.5 / / 1.0-\mathrm{s})$ and the long $(5 / / 10-s)$ duration condition associated with the first sample. The black cross indicates the $5 \tau$ value 


\section{THE AGE OF MATURITY IN TIME DISCRIMINATION ABILITIES}

The results of the modeling of WR in the second sample (selected sample) were close to those found in the first sample for the long durations, although the program found convergence slightly earlier, with a $5 \tau$ value at about seven years (6.8 years of age, 82 months) instead of eight to nine years. Indeed, the found function was $0.38\{1-\exp [-(x-$ $43.62) / 25936.48]\} *\{\exp [-(x-71.12) / 2.28] 0.16\}, S_{\text {squares }}=3.93, \mathrm{LSD}=0.04$. However, for the short durations (Figure 6), the program found a convergence point at birth $5 \tau=2.8$ months with the following equation: $1.56\{1-\exp [-(\mathrm{x}-103.49) / 15567.51]\} *\{\exp [-(\mathrm{x}+$ $5.38) / 1.54]+0.24\}$. These results suggest that when removing bad performers in temporal bisection, the time sensitivity did not change with age for the short duration, being already high from an early age, while it improves until about seven years for long durations.

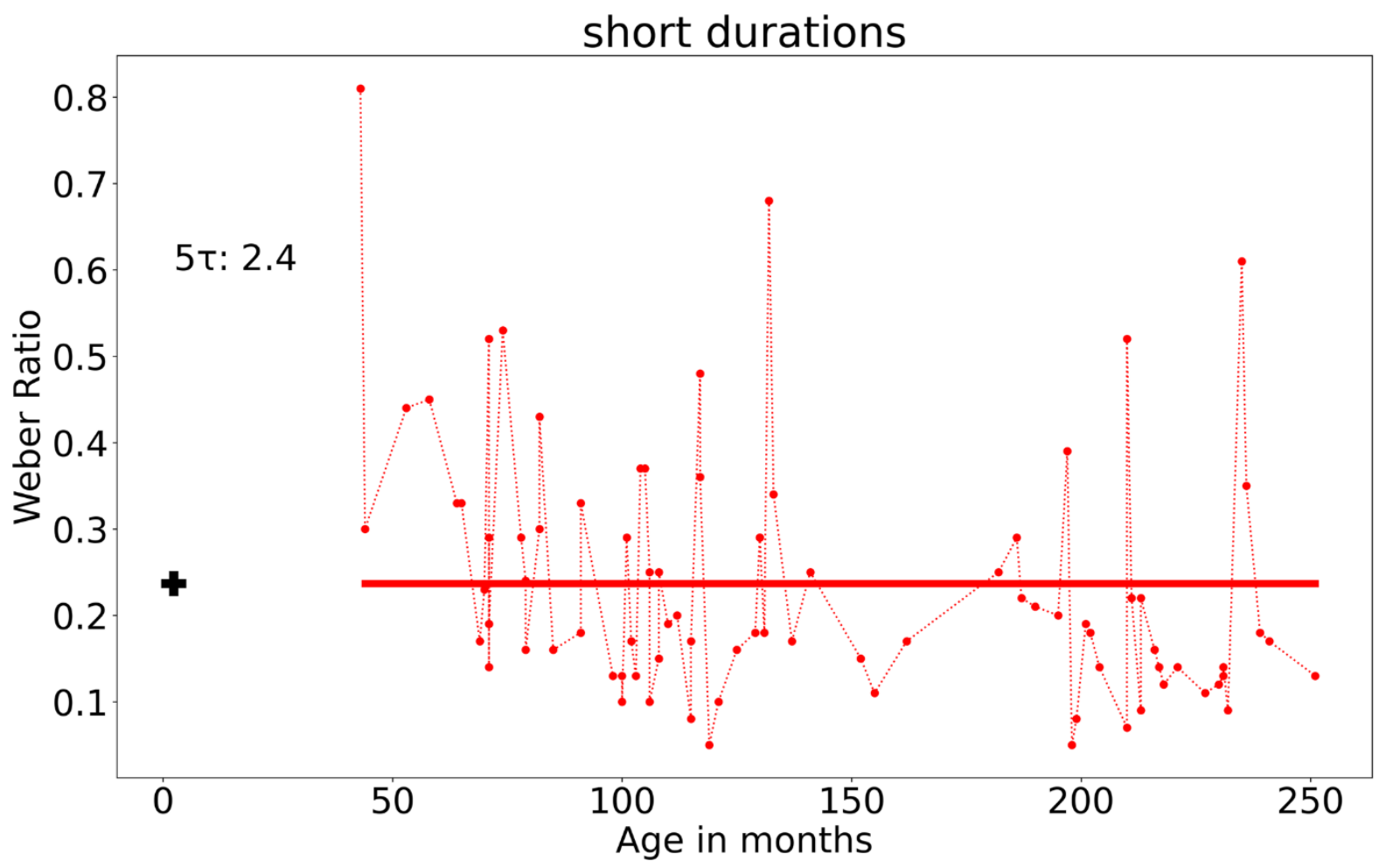

Figure 6. Empirical data (dotted lines) and fitted functions (continuous lines) of the bisection points plotted against the participants' age in months for the short (0.5/1.0- s) and long (5//10s) duration condition associated with the selected sample. The black cross indicates the $5 \tau$ value

\section{Discussion}

The aim of this study was to identify the age at which timing abilities mature, i.e., it reaches an adult-like level in a temporal bisection task, for both the processing of short durations of a few hundred milliseconds and that of longer durations of several seconds. The data obtained on a large sample of participants aged from three to 20 years was modeled using exponential shape functions. The modelling of data was carried out on two different samples. The first 


\section{THE AGE OF MATURITY IN TIME DISCRIMINATION ABILITIES}

included all participants (excluding those who failed to understand the task), regardless of their poor performance in the temporal bisection task. The second rejected "bad performers" ( $6 \%$ of the first sample). The cause of their poor performance was nevertheless not identified. It may be related to their low attention capacities (lower than that of the others), such that they sometimes responded randomly in bisection (Droit-Volet \& Wearden 2001), or their poor motivation for the tasks.

When we considered all participants, except those systematically giving only one answer (e.g., always short or always long), the developmental curve of the sensitivity to time (WR values) reached a floor threshold at the age of six years for the short durations and 8 years for the long durations. When we excluded the "bad performers" from this sample, the developmental curve was stable at about the same age for the long duration (seven years), and at earlier age for the short durations, before three years, i.e., as early as 2.4 months as suggested by the data modeling. In contrast, for the BP, our modeling was unable to find a point of convergence for long durations, regardless of the sample selected. We nevertheless succeeded to find a stabilization in the BP values through ages at about four years old for the whole sample and 16 years for the selected sample.

Although surprising, the modeling results for the BP are consistent with the behavioral results of developmental studies testing two or three age groups. Indeed, the failure of our modelingmodeling to converge to a value accounts for the absence of a age effect on BP found in the developmental studies (Droit-Volet \& Wearden, 2001; Droit-Volet \& Zélanti, 2013b; Droit-Volet et al., 2015). However, our model suggests that this absence of a age effect was mainly due to a great inter-individual difference in the BP values. This calls into question the averaged BP values obtained in the bisection studies. Wearden and Ferrara $(1995,1996)$ explained that the BP values fluctuate with the decision-making rules adopted by the participants according to the difficulty of the task. When the task is difficult, the decisional threshold varies according to the subjects' degree of confidence in their temporal judgment (Lamotte et al., 2017) By modeling her bisection data, Droit-Volet (2002) has shown that the decision threshold directly depends on the noise in the representation of durations in memory. And the representation of long durations in memory is particularly noisy, at least noisier than that of short durations. The fuzzy representation of long durations in memory might thus explain the great inter-individual variability in the BP values and the impossibility to find a stabilization point over the ages. Unlike for the long durations, the data modeling for the short durations indicated a convergence point at the age of four years for the whole sample and at the age of 16 years for the selected sample. Normally, with a more selective sample an inverse result should have been expected with an earlier rather than a later convergence age. This simply suggests that the averaged BP value for the short durations was biased by the results of children who did not succeed in the bisection task. From a mathematical point of view, it could be stated that our modelling becomes more sensitive as the individual differences are extracted. As such, the fit becomes more sensitive to inter-individual variations when children who failed the bisection task are removed. Without this bias, there was no converging value due to the absence of a age effect or a late convergence probably related to the development of decision-making skills.

Our data modeling is more informative and convincing for the WR values - the time sensitivity - because it showed clear results, which are in addition entirely consistent with those of developmental studies (Coull \& Droit-Volet, 2018; Droit-Volet, 2016). Indeed, it confirms that the time sensitivity increases with age. Furthermore, it clearly indicated an age threshold at which no further differences occur for the two samples. For the whole sample, the convergence age was six years for the short durations and $8 \frac{1}{2}$ years for the long durations. In other words, the time sensitivity in bisection stops improving at six years and at eight to nine 


\section{THE AGE OF MATURITY IN TIME DISCRIMINATION ABILITIES}

years for short and long durations, respectively. This provides additional evidence for key ages in the development of temporal abilities between five and eight years, with no difference being observed between eight- year-olds and adults. The WR values could significantly change between seven to nine years and adult age for longer durations than those tested in our studies (Droit-Volet \& Zélanti, 2013b, Droit-Volet et al., 2015). Our data modelling on the selected sample suggests that the point of convergence remained about the same for the long durations, at seven years instead of $81 / 2$ years. However, for the short durations, it was still earlier, i.e., at two months of age instead of six years. We have therefore been able to identify a developmental curve showing a decrease in the WR resulting in a stable value for both samples. However, it is important to highlight that the variability in the WR values was particularly high within our second sample, especially within long durations for children aged three to four years old. It is thus possible that part of the temporal responses were given by chance by these young children in the long duration condition, although their bisection curves were ordered with a significant increase of $\mathrm{p}$ (long) with increasing stimulus durations. The stabilization effect could thus have been detected even earlier if the participants with high WR were also removed from the sample. Nonetheless, this sorting of children is problematic in a developmental approach and it would take many participants to achieve this because accurate and low variating temporal performances are not representative of children at these young ages (Droit-Volet, 2016).

Jointly, our analyses based on the two samples confirm an earlier improvement in time sensitivity with short than long durations (Zélanti \& Droit-Volet, 2011). The developmental improvement in temporal performance is therefore mainly observed in the context of processing of long durations. This can be explained by the fact that short durations are processed more automatically than long durations (Grondin, 2010, 2016; Hallez \& Droit- Volet, 2017). Several studies have demonstrated that babies are able to judge stimulus durations of a few hundreds of milliseconds (Brannon et al., 2004; Delavenne et al., 2013; Henning \& Striano, 2011; Provasi et al., 2011). Zélanti and Droit-Volet (2011) have also shown that the processing of long durations requires more working memory and attention capacities than that of short durations. In the same way, Droit-Volet and Coull (2018) have found a significant effect of age in explicit time judgment but not in implicit time judgment. In addition, the age- related differences in the explicit time judgment were due to children's differences in attention and executive functions.

Our modeling of data in bisection therefore provided a new description of temporal development with key ages of maturity, but one that is entirely consistent with those observed in previous developmental studies using two or three age groups. Nevertheless, it is important to recognize the advantages and the limits of our approach. The number of participants per age and the amount of data available might be thought of as being a little inadequate in order to accurately match an age with the start of stabilization of timing parameters. Indeed, exponential decay functions were fitted with averages for each age in months, with only a few representatives available per group, at least for the ages of 12 and 15 years. If we had been able to access a large database with multiple representatives for each of the 324 months, it might have been possible to include variance within the same model. Nonetheless, the inter- individual variance in our data was very high for the three-year-old group but not for the other age groups (see Figures), and it should be noted that we tested a greater number of children $(\mathrm{N}=15-17)$ in the younger age groups (four and five years). However, our method was based on the ages in months and not on the number of children per age range. In this case, all the data with very few representatives can be taken into account with very few. Furthermore, if the inter-individual variance had been too high a point of convergence could not have been obtained, as we have found for the BP in the long duration range. In other words, if the data in a noisy system converge at any given moment, then one can be confident that a stabilizing effect exists. We 


\section{THE AGE OF MATURITY IN TIME DISCRIMINATION ABILITIES}

can therefore trust our model and its conclusions for the converged data when these are not too far outside the represented ages.

In conclusion, the originality of our study is to have succeeded in identifying age thresholds in time sensitivity above which no further changes are observed, thus indicating the attainment of maturity in timing abilities. From a clinical perspective, these ages can be used as reference in the early diagnosis of timing deficits. Timing deficits can be diagnosed from early childhood in a temporal bisection task with short durations, and at the age of six or seven years with long durations. As demonstrated by Provasi et al. (2011), it is possible to use a temporal bisection task with short durations in babies. Furthermore, Rammsayer and his colleagues have showed that performance in explicit timing tasks is a better predictor of intelligence than performance on other cognitive subtests (Rammsayer \& Brandler, 2007; Troche \& Rammsayer, 2009). The early detection of timing deficits by means of the bisection task can therefore permit early remedial treatment, thus promoting a rapid improvement in timerelated and cognitive capacities during a critical period of development, which is characterized by high cerebral plasticity.

\section{Acknowledgements}

The authors thank Pierre Zélanti who was research assistant and collected a large proportion of the participants' data.

\section{References}

Allan, L. G., \& Gerhardt, K. (2001). Temporal bisection with trial referents. Percept. Psychophysis., 63(3), 524-540. doi: 10.3758/BF03194418

Allan, L. G., \& Gibbon, J. (1991). Human bisection at the geometric mean. Learn. Motiv., 22(1), 3958. doi: 10.1016/0023-9690(91)90016-2

Berg, R. W., \& Ditlevsen, S. (2013). Synaptic inhibition and excitation estimated via the time constant of membrane potential fluctuations. J. Neurophysiol., 110, 1021-1034. doi: 10.1152/jn.00006.2013.

Brannon, E. M., Roussel, L. W., Meck, W. H., \& Woldorff, M. (2004). Timing in the baby brain. Cogn. Brain Res., 21(2), 227-233. doi: 10.1016/j.cogbrainres.2004.04.007

Brown, B. L., Höhn, S., Faure, A., Von Hörsten, S., Le Blanc, P., Desvignes, N., El Massioui, N., \& Doyère, V. (2011). Temporal sensitivity changes with extended training in a bisection task in a transgenic rat model. Front. Integr. Neurosci., 5, 44. doi: 10.3389/fnint.2011.00044

Casey, B. J., Tottenham, N., Liston, C., \& Durston, S. (2005). Imaging the developing brain: What have we learned about cognitive development? Trends Cogn. Sci., 9, 104-110. doi: 10.1016/j.tics.2005.01.011

Casini, L., PechGeorgel, C., \& Ziegler, J. C. (2018). It's about time: revisiting temporal processing deficits in dyslexia. Developmental Science, 21(2), e12530. doi: 10.1111/desc. 12530

Cheyne, C., \& Worrall, J. (2006). Rationality and Reality: Conversations with Alan Musgrave. Dordrecht, The Netherlands: Springer Science \& Business Media.

Church, R. M., \& Deluty, M. Z. (1977). Bisection of temporal intervals. Journal of Experimental Psychology: Animal Behavior Processes, 3(3), 216-228. doi: 10.1037/0097-7403.3.3.216

Coull, J. T., \& Droit-Volet, S. (2018). Explicit understanding of duration develops implicitly through action. Trends in Cognitive Sciences, 22(10), 923-937. doi: 10.1016/j.tics.2018.07.011

Delavenne, A., Gratier, M., \& Devouche, E. (2013). Expressive timing in infant-directed singing between 3 and 6 months. Infant Behavior and Development, 36(1), 1-13. doi:

10.1016/j.infbeh.2012.10.004 


\section{THE AGE OF MATURITY IN TIME DISCRIMINATION ABILITIES}

Dempster, F. N., \& Brainerd, C. J. (1995). Interference and inhibition in cognition. Academic Press, New York, NY, USA.

Droit-Volet, S. (2002). Scalar timing in temporal generalization in children with short and long stimulus durations. The Quarterly Journal of Experimental Psychology, A, 55, 1193-1209. doi: 10.1080/02724980244000161

Droit-Volet S. (2013). Time perception in children: A neurodevelopmental approach. Neuropsychologia, 51, 220-234. doi: 10.1016/j.neuropsychologia.2012.09.023

Droit-Volet, S. (2016). Development of time. Curr. Opin. Behav. Sci., 8, 102-109. doi: 10.1016/j.cobeha.2016.02.003.

Droit-Volet, S. (2017). Time dilation in children and adults: the idea of a slower internal clock in young children tested with different click frequencies. Behavioural Processes, 138, 152-159. doi: 10.1016/j.beproc.2017.03.005

Droit-Volet, S., Clément, A., \& Fayol, M. (2008). Time, number, and length: Similarities and differences in bisection behavior in children and adults. Quarterly Journal of Experimental Psychology, 61(12), 1827-1846. doi: 10.1080/17470210701743643.

Droit-Volet, S., \& Coull, J. T. (2016). Distinct developmental trajectories for explicit and implicit timing. Journal of Experimental Child Psychology, 150, 141-154. doi: 10.1016/j.jecp.2016.05.010

Droit-Volet, S., \& Izaute, M. (2009). Improving time discrimination in children and adults in a temporal bisection task: The effects of feedback and no forced choice on decision and memory processes. The Quarterly Journal of Experimental Psychology, 62(6), 1173-1188. doi: 10.1080/17470210802384180

Droit-Volet, S., \& Rattat, A.C. (2007). A further analysis of temporal bisection behavior in children with and without reference memory: the similiarity and the partition task. Acta Psychologica, 125(2), 240-256. doi: 10.1016/j.actpsy.2006.08.003

Droit-Volet, S., Tourret, S., \& Wearden, J. H. (2004). Perception of the duration of auditory and visual stimuli in children and adults. Quarterly Journal of Experimental Psychology Section A, 57(5), 797-818. doi: 10.1080/02724980343000495

Droit-Volet, S., \& Wearden, J. H. (2001). Temporal bisection in children. Journal of Experimental Child Psychology, 80(2), 142-159. doi: 10.1006/jecp.2001.2631

Droit-Volet, S., \& Wearden, J. H. (2002). Speeding up an internal clock in children? Effects of visual flicker on subjective duration. The Quarterly Journal of Experimental Psychology: Section B, 55(3), 193-211. doi: 10.1080/02724990143000252

Droit-Volet, S., Wearden, J. H., \& Zélanti, P. S. (2015). Cognitive abilities required in time judgment depending on the temporal task used: a comparison of children and adults. Quarterly Journal of Experimental Psychology, 68(11), 2216-2242. doi: 10.1080/17470218.2015.1012087

Droit-Volet, S., \& Zélanti, P. S. (2013). Development of time sensitivity and information processing speed. PloS one, 8(8), e71424. doi: 10.1371/journal.pone.0071424

Droit-Volet, S., \& Zélanti, P. S. (2013). Development of time sensitivity: duration ratios in time bisection. The Quarterly Journal of Experimental Psychology, 66(4), 671-686. doi: 10.1080/17470218.2012.712148

Droit-Volet, S., Zélanti, P. S., Dellatolas, G., Kieffer, V., El Massioui, Brown, B. L., Doyère, V., Joëlle Provasi, J., \& Grill, J. (2013). Time perception in children treated for a cerebellar medulloblastoma. Research in Developmental Disabilities, 34(1), 480-494. doi: 10.1016/j.ridd.2012.09.006

Forster, M., \& Sober, E. (1994). How to tell when simpler, more unified, or less ad hoc theories will provide more accurate predictions. The British Journal for the Philosophy of Science, 45(1), 1-35. doi: 10.1093/bjps/45.1.1 


\section{THE AGE OF MATURITY IN TIME DISCRIMINATION ABILITIES}

Giersch, A., Lalanne, L., Isope, P. (2016). Implicit timing as the missing link between neurobiological and self disorders in schizophrenia? Front. Hum. Neurosci., 10, 303. doi: 10.3389/fnhum.2016.00303

Giersch, A., \& Mishara, A.L. (2017). Disrupted continuity of subjective time in the milliseconds range in the self-disturbances of schizophrenia: convergence of experimental, phenomenological and predictive coding accounts. J. Consc. Stud., 24: 62-87.

Graham-Schmidt, K. T., Martin-Iverson, M. T., Holmes, N. P., \& Waters, F. A. (2016). When one's sense of agency goes wrong: Absent modulation of time perception by voluntary actions and reduction of perceived length of intervals in passivity symptoms in schizophrenia. Consciousness and cognition, 45, 9-23.Grondin, S. (2010). Timing and time perception: a review of recent behavioral and neuroscience findings and theoretical directions. Attention, Perception, \& Psychophysics, 72(3), 561-582. doi: 10.3758/APP.72.3.561

Grondin, S. (2010). Timing and time perception: A review of recent behavioral an neuroscience findings and theoretical directions. Atten. Percept. Psychophys., 72(3), 561-582. doi: 10.3758/APP.72.3.561

Grondin, S. (2016). Perception and Attention. In Psychology of Perception (pp. 123-135). Springer, Cham.

Hallez, Q., \& Droit-Volet, S. (2017). High levels of time contraction in young children in dual tasks are related to their limited attention capacities. Journal of Experimental Child Psychology, 161, 148-160. doi: 10.1016/j.jecp.2017.04.013

Hallez, Q., \& Droit-Volet, S. (2019) Timing in a dual-task in children and adults: when the interference effect is higher with concurrent non-temporal than temporal information. $J$. Cogn. Psychol., 31, 34-48. doi: 10.1080/20445911.2019.1567519

Henning, A., \& Striano, T. (2011). Infant and maternal sensitivity to interpersonal timing. Child Dev, 82, 916-931. doi:10.1111/j.1467-8624.2010.01574.x

Kahana, M. J., \& Adler, M. (2017). Note on the power law of forgetting. bioRxiv, 173765. doi: $10.1101 / 173765$

Kasprowicz, M., Czosnyka, M., Soehle, M., Smielewski, P., Kirkpatrick, P. J., Pickard, J. D., \& Budohoski, K. P. (2012). Vasospasm shortens cerebral arterial time constant. Neurocritical care, 16(2), 213-218. doi: 10.1007/s12028-011-9653-1

Killeen, P. R., Fetterman, J. G., \& Bizo, L. A. (1997). Time's cause. In C. M. Bradshaw \& E. Szabadi (Eds.), Time and behavior: Psychological and neurobehavioral analyses (pp. 79-131). Amsterdam: Elsevier, North-Holland. doi: 10.1016/S0166-4115(97)80055-6

Lagarias, J. C., Reeds, J. A., Wright, M. H., \& Wright, P. E. (1998). Convergence properties of the Nelder-Mead simplex method in low dimensions. SIAM Journal on Optimization, 9(1), 112147. doi: $10.1137 / \mathrm{S} 1052623496303470$

Lamotte, M., Droit-Volet, S., \& Izaute, M. (2017). Confidence judgment in a temporal generalization task: Accuracy and sensitivity to task difficulty. L'Année psychologique, 117, 275-2988. doi: 10.4074/S0003503317000537

Lewis, P. A., \& Miall, R. C. (2009). The precision of temporal judgement: Milliseconds, many minutes, and beyond. Philosophical ransactions of the Royal Society B, 364, 1897-1905.

Liptak, B. G. (2003). Instrument Engineers' Handbook, Volume One: Process Measurement and Analysis. CRC press.

Matell, M. S., \& Meck, W. H. (2000). Neuropsychological mechanisms of interval timing behavior. Bioessays, 22(1), 94-103. doi: 10.1002/(SICI)15211878(200001)22:1<94:AIDBIES14>3.0.CO;2-E 


\section{THE AGE OF MATURITY IN TIME DISCRIMINATION ABILITIES}

Matell, M. S., \& Meck, W. H. (2004). Cortico-striatal circuits and interval timing: coincidence detection of oscillatory processes. Cognitive brain research, 21(2), 139-170. doi: 10.1016/j.cogbrainres.2004.06.012

McCormack, T., Brown, G. D. A., Maylor, E. A., Darby, A., \& Green, D. (1999). Developmental changes in time estimation: Comparing childhood and old age. Developmental Psychology, 35(4), 1143-1155. doi: 10.1037/0012-1649.35.4.1143

Merchant, H. Harrington, D \& Meck, W. (2013). Neural basis of the perception and estimation of time. Annual review of Neurosciences, 36, 313-336. doi: 10.1146/annurev- neuro-062012170349

Mundy, P. (2018). A review of joint attention and social-cognitive brain systems in typical development and autism spectrum disorder. European Journal of Neuroscience, 47(6), 497514. doi: 10.1111/ejn.13720

Nelder, J. A., \& Mead, R. (1965). A simplex method for function minimization. The computer journal, 7(4), 308-313. doi: 10.1093/comjnl/7.4.308

Olsson, D. M., \& Nelson, L. S. (1975). The Nelder-Mead simplex procedure for function minimization. Technometrics, 17(1), 45-51. doi: 10.2307/1267998

Provasi, J., Rattat, A. C., \& Droit-Volet, S. (2011). Temporal bisection in 4-month-old infants. Journal of Experimental Psychology: Animal Behavior Processes, 37(1), 108. doi: $10.1037 / \mathrm{a} 0019976$.

Qiang, M., \& Zhang, L. (2015) On line drawing method of mud pump performance curve based on Win CC and Matlab. Autom. Instrum., 2015, 60

Rall, W. (1960). Membrane potential transients and membrane time constant of motoneurons. Experimental Neurology, 2(5), 503-532. doi: 10.1016/00144886(60)90029-7

Rammsayer, T. H., \& Brandler, S. (2007). Performance on temporal information processing as an index of general intelligence. Intelligence, 35, 123-139. doi: 10.1016/j.intell.2006.04.007

Rattat, A. C., \& Droit-Volet, S. (2005). The long-term retention of time: A developmental study. The Quarterly Journal of Experimental Psychology Section B, 58(2), 163-176. doi:

10.1080/02724990444000096

Rattat, A. C., \& Droit-Volet, S. (2012). What is the best and easiest method of preventing counting in different temporal tasks? Behavior Research Methods, 44(1), 67-80. doi: 10.3758/s13428011-0135-3

Roy, M., Grondin, S., \& Roy, M. A. (2012). Time perception disorders are related to working memory impairment in schizophrenia. Psychiatry research, 200(2-3), 159-166.

Sowell, E. R., Thompson, P. M., Holmes, C. J., Batth, R., Jernigan, T. L., \& Toga, A. W. (1999). Localizing age-related changes in brain structure between childhood and adolescence using statistical parametric mapping. NeuroImage, 9(6), 587-597. doi: 10.1006/nimg.1999.0436

Tiganj, Z., Hasselmo, M. E., \& Howard, M. W. (2015). A simple biophysically plausible model for long time constants in single neurons. Hippocampus, 25(1), 27-37.

Troche, S. J., \& Rammsayer, T. H. (2009) The influence of temporal resolution power and working memory capacity on psychometric intelligence. Intelligence, 37, 479-486.

Tsujimoto, S. (2008). The prefrontal cortex: Functional neural development during early childhood. The Neuroscientist, 14(4), 345-358. doi: 10.1177/1073858408316002

Wearden, J. H. (1991). Human performance on an analogue of an interval bisection task. The Quarterly Journal of Experimental Psychology Section B, 43(1b), 59-81.

Wearden, J. H., (2016). The psychology of time perception. Springer.

Wearden, J. H., \& Ferrara, A. (1995). Stimulus spacing effects in temporal bisection by humans. Quarterly Journal of Experimental Psychology, 48B, 289 - 310. 


\section{THE AGE OF MATURITY IN TIME DISCRIMINATION ABILITIES}

Wearden, J. H., \& Ferrara, A. (1996). Stimulus range effects in temporal bisection by humans. Quarterly Journal of Experimental Psychology, 49B, 24-44.

Zélanti, P. \& Droit-Volet, S. (2011). Cognitive abilities explaining age-related changes in time perception of short and long durations. Journal of Experimental Child Psychology, 109(2), 143-157. doi: 10.1016/j.jecp.2011.01.003

Zélanti, P. S., \& Droit-Volet, S. (2012). Auditory and visual differences in time perception? An investigation from a developmental perspective with neuropsychological tests. Journal of Experimental Child Psychology, 112(3), 296-311. doi: 10.1016/j.jecp.2012.01.003

Zylberberg, A., Dehaene, S., Mindlin, G. B., \& Sigman, M. (2009). Neurophysiological bases of exponential sensory decay and top-down memory retrieval: a model. Frontiers in computational neuroscience, 3(4). doi: 10.3389/neuro.10.004.2009 